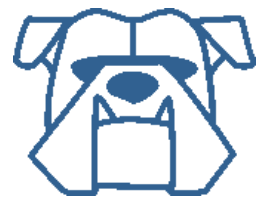

Kettering University

Digital Commons @ Kettering University

8-21-2019

\title{
An Optical-based Technique to Obtain Vibration Characteristics of Rotating Tires
}

Aakash Mange

Theresa Atkinson

Jennifer Bastiaan

Javad Baqersad

Follow this and additional works at: https://digitalcommons.kettering.edu/mech_eng_facultypubs

Part of the Mechanical Engineering Commons 


\section{An Optical-Based Technique to Obtain Vibration Characteristics of Rotating Tires}

Aakash Mange, Theresa Atkinson, Jennifer Bastiaan, and Javad Baqersad, Kettering University, USA

\section{Abstract}

The dynamic characteristics of tires are critical in the overall vibrations of vehicles because the tireroad interface is the only medium of energy transfer between the vehicle and the road surface. Obtaining the natural frequencies and mode shapes of the tire helps in improving the comfort of the passengers. The vibrational characteristics of structures are usually obtained by performing conventional impact hammer modal testing, in which the structure is excited with an impact hammer and the response of the structure under excitation is captured using accelerometers. However, this approach only provides the response of the structure at a few discrete locations, and it is challenging to use this procedure for rotating structures. Digital Image Correlation (DIC) helps in overcoming these challenges by providing the full-field response of the structure. Although there have been many experiments on tires, there are few published papers that investigate the full-field dynamics of rotating tires at high rotating speeds. In the current work, the Kettering University Formula SAE (FSAE) vehicle is loaded on a chassis dynamometer for the purpose of performing a tire experiment. A pair of high-speed cameras capture high-resolution images to obtain the response of the tire sidewall in stationary and rotating conditions. The modal characteristics of the tire are obtained by processing these images. The results reveal the resonant frequencies and the operational deflection shapes of the loaded and unloaded tire in stationary and rotating conditions. The current article provides full-field information about the dynamics of tires at high rotating speeds for engineers and scientists in the field.

\section{History}

Received: 27 Mar 2019 Revised: 20 May 2019 Accepted: 01 Aug 2019 e-Available: 21 Aug 2019

\section{Keywords}

DIC, Tire, Vibration, Mode shape, Operating shapes

\section{Citation}

Mange, A., Atkinson, T., Bastiaan, J., and

Baqersad, J., "An OpticalBased Technique to Obtain Vibration Characteristics of Rotating Tires," SAE Int. J. Veh. Dyn., Stab., and NVH 3(3):197-208, 2019, doi:10.4271/10-03-03-0013.

ISSN: 2380-2162 e-ISSN: 2380-2170 


\section{Introduction}

ecently, there has been increased interest in improving the ride quality of ground vehicles; this makes it crucial to understand the vibrational characteristics of tires. The excitation from the road can ultimately reach the cabin, which affects the comfort and safety of the passengers [1]. To reduce these vibrations, it is important to obtain the vibrational characteristics of the tires. Several numerical models have been developed to understand the modal characteristics of tires. However, these models must be validated using experimental data. Therefore, it is essential to develop testing methods that can help validate the results obtained through the theoretical and numerical models.

Traditionally, accelerometers are used to obtain the vibrational characteristics of tires. These sensors are inexpensive and have high sensitivity [2]. They have been used to perform impact testing and to capture the mode shapes of tires in different conditions []ㅡ. However, accelerometers can only provide information at their discrete measurement locations, and they may induce mass loading effects. Furthermore, it is challenging to use these sensors to measure the dynamics of rolling tires because of the wiring and data transmission issues.

To overcome these drawbacks, some researchers have developed noncontact techniques to measure the vibration response of tires. For example, laser-based tire sensors are sensors embedded in a module that can be attached to the rim. This type of sensor is highly robust and measures the deflections of the tire carcass in rolling conditions $[\underline{4}, \underline{5}]$. However, they are highly sensitive to Light Emitting Diode (LED) alignment. Furthermore, the sensor assembly must be attached to the rotating tire, and hence a dead weight is required for balancing. To eliminate these concerns, researchers used Laser Doppler Vibrometers (LDVs) to study the vibrational characteristics of tires. This technique can be used to measure high-frequency vibrations; however, it requires a complex experimental setup due to its laser alignment requirement. Another disadvantage of this method is that it cannot simultaneously measure the entire response of a tire; thus, it is time consuming.

DIC is a noncontact optical technique that has been widely used to obtain the full-field deformation of structures. The technique was developed in the 1980s by Peters, Ranson, Sutton, and Chu et al. $[\underline{6}, \underline{7}, \underline{8}]$ and has found increased applications in the field of structural dynamics with advancements in computer technology and digital cameras. The technique works on the basic principle of triangulation [9]. The DIC system is calibrated before acquiring images for the threedimensional (3D) reconstruction. Detailed explanation of the theory behind this stereophotogrammetry technique can be found in $[\underline{9}, \underline{10}, \underline{11}, \underline{12}, \underline{13}]$. This approach has been recently used for vibration measurements [14] and structural health monitoring [15]. The methodology has been applied to obtain dynamic characteristics of bridges $[16,17,18]$, wind turbines $[19,20,21,22]$, helicopter rotors [23], human skin [13], and civil infrastructure [24]. The high-speed cameras of the DIC system capture images of the structure when it is vibrating, and the time domain information is processed to obtain the modal characteristics. This noncontact technique tracks each subset of points on the test structure in time and obtains a grayscale value for each subset. By comparing the deformed image with the undeformed reference image, the matching subsets of points are identified. After the correlation is obtained, the fullfield deformation of the structure is calculated. Applying the Fast Fourier Transform (FFT) to this time domain data, the natural frequencies and mode shapes of the structure are obtained in the frequency domain. This technique is robust, full-field, and noncontacting; it has been extended in the automotive industry by various researchers $[\underline{25}, \underline{26}]$.

Although there have been many experiments on tires, there are few published papers that investigate the full-field dynamics of rotating tires at high rotation speeds. Modes of a rotating tire in the tread section have been studied by researchers [27]. However, this article focuses on studying the modes of the sidewall of a tire in rotating conditions. The application of DIC to tire dynamic measurements, and especially sidewall vibration, is investigated. A DIC measurement has been performed on a Kettering University FSAE racing tire in a non-rotating condition to obtain its mode shapes. A new set of Hoosier racing tires was used. The results from this test are compared with those obtained from a conventional modal analysis method to validate the approach. The DIC method was then used to experimentally measure the resonant frequencies and operational deflection shapes of the tire in rolling conditions. The results of this work can provide engineers with a new technique that can be used to obtain the rotational dynamics of tires. The current article proposes using DIC as a noncontact full-field approach to measure dynamics of tires at high rotation speeds which is difficult to do with contact-based testing methods. The results from this work show the dominating effect of harmonics that has not been demonstrate in detail before. Attenuating the harmonics of the rotation frequencies would help in better understanding the modal characteristics of tires in rolling conditions.

\section{Digital Image Correlation}

Stereophotogrammetry is a noncontacting measurement approach that uses a series of images recorded using a pair of digital cameras to find coordinates of points or patterns. The fundamental concept of photogrammetry is how to correlate object dimensions to photograph dimensions (see Figure 1). A single camera can be used to measure the displacement of objects in a planar motion. However, a 3D measurement must be performed using stereo cameras that are locked in place during the test. The photos are recorded simultaneously and are saved on a record. A triangulation technique using a raytracing process is used to determine the coordinate of the features in the test structure.

The DIC technique works based on grayscale variations of a continuous pattern. The area of the test structure must 
FIGURE 1 The fundamentals of photogrammetry showing how the sensor size and pixel size can be correlated to the field of view and object sample size, respectively [28].

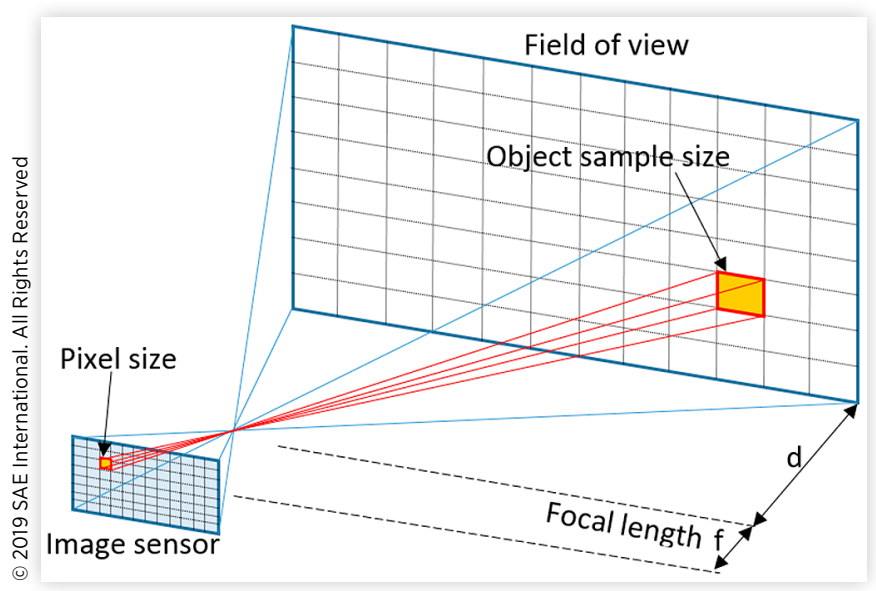

be prepared before the measurement. The surface preparation is usually performed by applying a high contrast speckle pattern on the structure. After surface preparation, a series of pictures are recorded using stereo cameras. The DIC method works by creating overlapping facets on the total area of interest. A facet size is usually 15-30 pixels square; thus, it includes several dots of the pattern (each dot is usually 3-7 pixels). Because the speckle pattern is randomly created, each facet possesses a unique light intensity value, and the software can recognize the movement of each facet in different stages. The displacement and strain over the area of interest are calculated by correlating each fact to the corresponding facet in the reference stage (usually the first stage). This approach can provide a relatively continuous measurement on the patterned area of the structure and can be called a full-field measurement technique in the line of sight of the cameras (see Figure 2).

\section{Conventional Modal Analysis}

The conventional modal analysis was performed on the nonrotating tire to obtain mode shapes and resonant frequencies. These results are compared to the DIC results to validate the approach. For the modal hammer impact testing, the FSAE tire was excited using an impact hammer, and the response was captured using accelerometers that were attached to the tire with an adhesive. A Dytran impact hammer with a metal tip, which had a sensitivity of $\sim 10 \mathrm{mV} / \mathrm{lb}_{\mathrm{f}}$, was used. The metal tip was employed to excite the high-frequency modes of the tire. The response of the tire was captured using two accelerometers that were mounted to the tire. The unidirectional accelerometers were attached to different measurement locations such that these were not located at the node of a mode.
FIGURE 2 Full-field results obtain using DIC for analysis of an exhaust muffler [29].

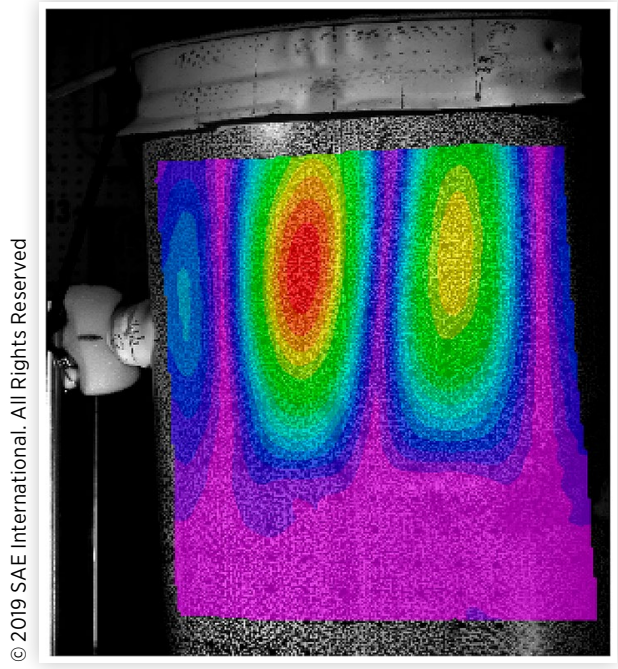

Trial measurements were performed to ensure this. Figure 3 shows the location of the accelerometers. The entire sidewall of the tire was divided into 36 measurement points. A roving impact hammer modal test was carried out for two different loading conditions of the tire. One test was performed when the tire was stationary and loaded on the drum roller, and another test was performed when the non-rotating tire was not loaded on the chassis dynamometer (a jack was used to lift the vehicle in this case). A 12-channel LMS data acquisition system was used to record the response. A bandwidth of $512 \mathrm{~Hz}$ was chosen along with 1024 spectral lines to obtain a fine frequency resolution of $0.5 \mathrm{~Hz}$. For each measurement point, five Frequency Response Functions (FRFs) were averaged. The coherence and power spectral density plots were observed during all the measurements. As the coherence plot quantifies the relationship between input and output, it was

\section{FIGURE 3 Photograph showing the locations of} accelerometers for impact hammer modal testing. The tire is mounted to the vehicle and loaded on the dynamometer.

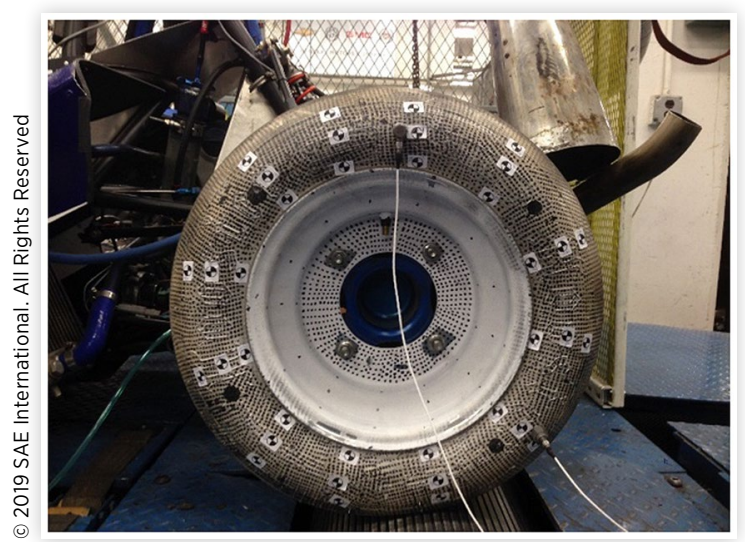


FIGURE 4 PolyMAX diagram obtained using conventional impact hammer modal testing for the tire in the unloaded condition, and the mode shapes at the respective resonant frequencies.

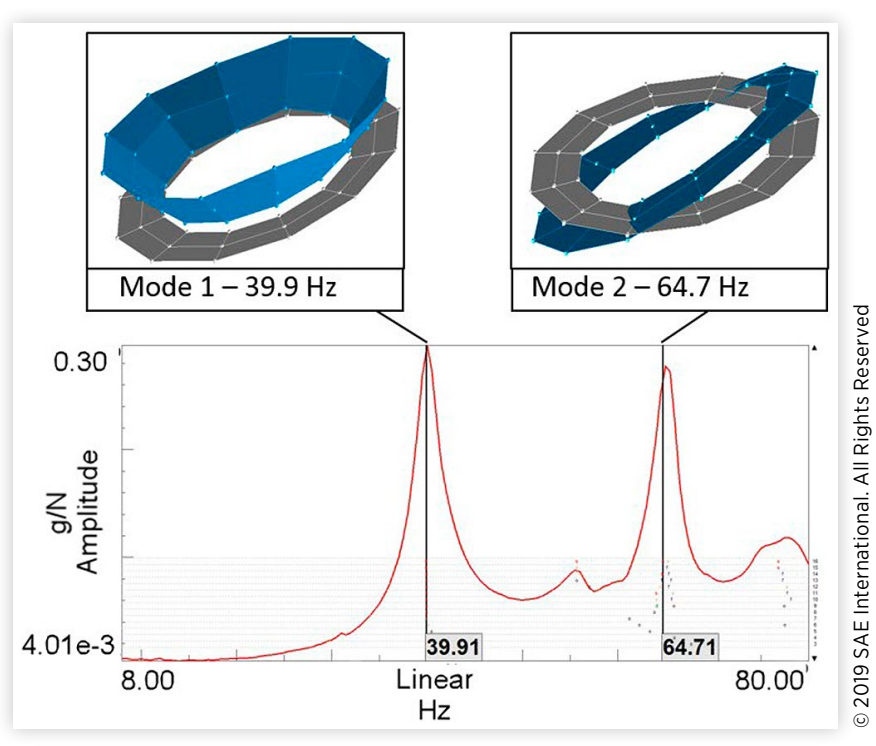

ensured that a good coherence of close to 1 was obtained in the measurements. The coherence tended to drop off in the higher frequency ranges, but was very good at low frequencies. Using a curve fitting technique, the modal parameters were obtained. The results are shown in Figures 4 and $\underline{5}$.

As shown in Figure 4, a small bandwidth of 8 to $80 \mathrm{~Hz}$ was chosen and these bands were curve-fitted using a 16-order polynomial. The graph shows that there are stable poles at the peaks of the $39.9 \mathrm{~Hz}$ and $64.7 \mathrm{~Hz}$ frequencies. These are the resonant frequencies of the tire in the unloaded condition. Mode shapes of the tire in this condition are obtained by choosing the stable poles. A similar procedure was followed

FIGURE 5 Mode shape of tire sidewall in the loaded condition at $59.4 \mathrm{~Hz}$; result obtained using conventional impact hammer modal testing.

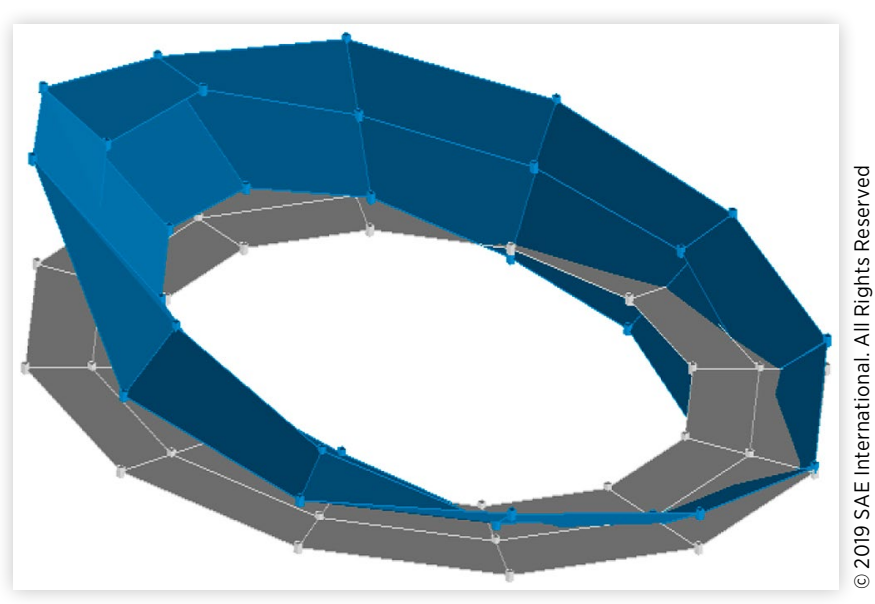

to obtain the natural frequencies and mode shapes of the FSAE tire in the loaded condition; one such mode shape is illustrated in Figure 5. It should be noted that the only mode shapes obtained for the tire were the ones that showed major deformations in the sidewall of the tire. Figure 5 shows a mode shape of the non-rotating tire when it is loaded on the dynamometer, with an associated frequency of $59.4 \mathrm{~Hz}$. This shape is similar to the mode shape of the tire at $64.7 \mathrm{~Hz}$ when it is in the unloaded condition. Because the tire was loaded on the drum roller, one side of the tire was in a fixed condition; hence, the nature of the mode shape changed.

\section{Modal Analysis Using Digital Image Correlation}

Figure 6 shows the experimental setup. The Kettering University FSAE car was loaded on a Mustang chassis dynamometer to obtain the operational deflection shapes of the tire at different speeds and loading conditions. Since the machine was a rear-wheel-drive dynamometer, the testing was performed on the left rear tire. The drum roller had multiple cleats that provided continuous cyclic excitation to the tire. The bumps and gaps on the roller (as shown in Figure 7) provide periodic excitation. As demonstrated in Figure 6, a pair of high-speed cameras recorded the deformation of the tire when it was stationary and when it was rotating. Frame rates of $500 \mathrm{fps}$ and $1000 \mathrm{fps}$ were used for non-rotating and rotating test cases, respectively. In order to reduce the motion blur, a small shutter time was implemented. Highintensity lights were used to enhance the illumination for capturing the images.

The first step in performing a DIC measurement is the creation of a speckle pattern on the test structure. To improve the accuracy of the results, it is essential for the pattern to be high-contrast and nonreflective in nature. This speckle pattern reduces uncertainty and noise during point tracking and enhances the spatial resolution of the measurement. The DIC system divides the structure of interest into smaller subsets of speckles, and these subsets are tracked by the cameras to obtain the deformation of the test structure [14].

Figure 8 shows the tire with the finalized speckle pattern. To achieve this pattern, the tire is painted white at first. Then a marker is used to create the black speckles on the tire. After creating the speckle pattern on the tire, the experimental setup must be calibrated in order to reduce the perspective distance between the tire and the DIC system. This is done using a calibration plate. The calibration plate contains a pattern of uniformly distributed coded and uncoded targets. Around 20 images are captured when rotating and translating the calibration plate in different orientations. Analyzing the rigid calibration target, the location of the optical targets is recognized in the stereo camera pair using an ellipse finder algorithm. This 


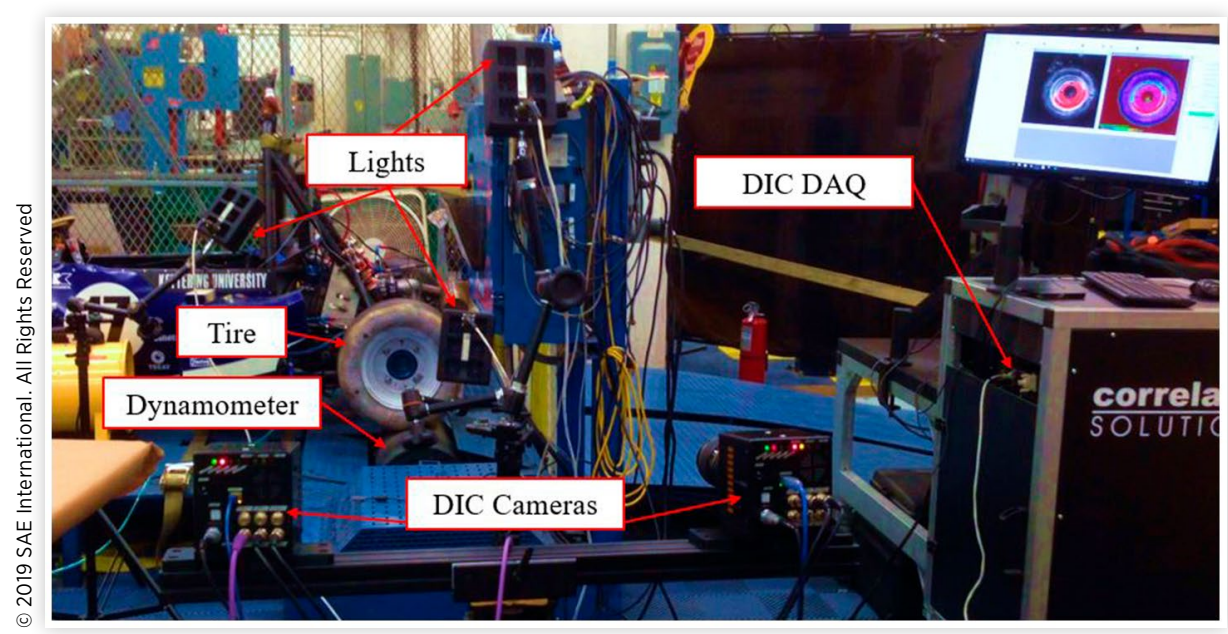

procedure calculates the intrinsic and extrinsic parameters of the high-speed cameras using a triangulation algorithm that compensates for lens distortions. At the end of this calibration procedure, the software defines a three-dimensional coordinate system on the test surface to remove any measurement bias. The experimentation is then performed for non-rotating and rotating conditions of the tire.

It is very challenging to measure the tread vibration with the DIC setup. The DIC system would need to be installed beneath the tire to capture tread deformation, and this would be difficult as the tire is rolling on the dynamometer. Gillespie [30] states that tire sidewall resonances are present in the lower frequency region which is of great interest because these low frequency modes are not only easily excited but also directly transmit the road vibrations to the vehicle.

FIGURE 7 Photograph showing the cleats on the dynamometer.

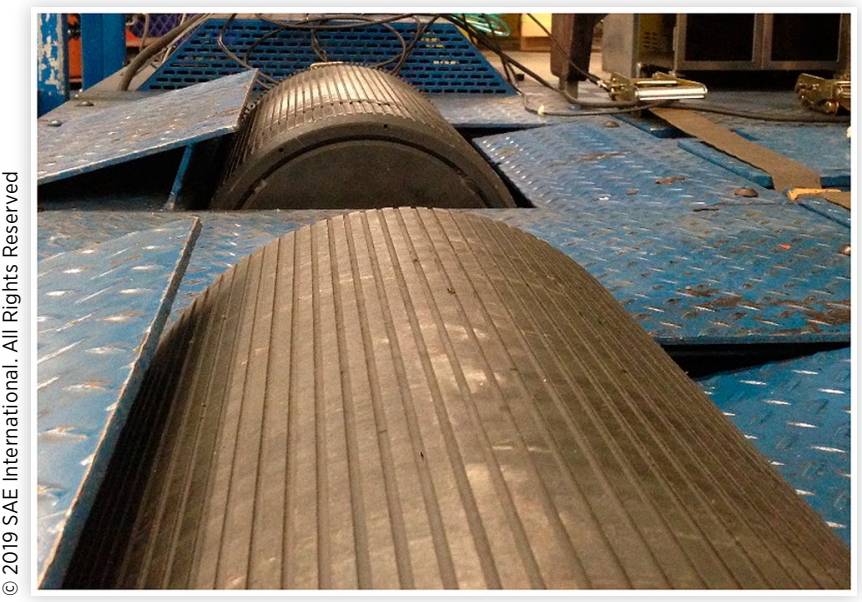

(c) 2019 SAE International. All Rights Reserved.
The non-rotating test was performed for both the loaded and unloaded cases. To perform the measurement, the tire was excited at a single point using a modal impact hammer, and the response of the tire to this excitation was captured using the DIC system. The images captured by the high-speed cameras were processed to obtain the time domain displacement of the tire. Performing an FFT on the time domain data, the frequency domain data were obtained. The results in the frequency domain were analyzed to acquire the modal characteristics of the tire. Figure 9 shows the operational deflection shapes of the tire when it was not loaded; to perform this measurement, the tire was attached to the hub and lifted from the ground. The boundary condition of the unloaded test case was similar to that of the loaded test case, with the only difference being that the vehicle was lifted using a jack and hence the tire was no longer loaded on the dynamometer. This unloaded test was performed for the non-rotating condition of the FSAE tire.

Figure 9 shows the resonant frequencies of the unloaded tire at $39.6 \mathrm{~Hz}$ and $65.3 \mathrm{~Hz}$. There is a strong correlation

\section{FIGURE 8 Detail of the speckle pattern.}

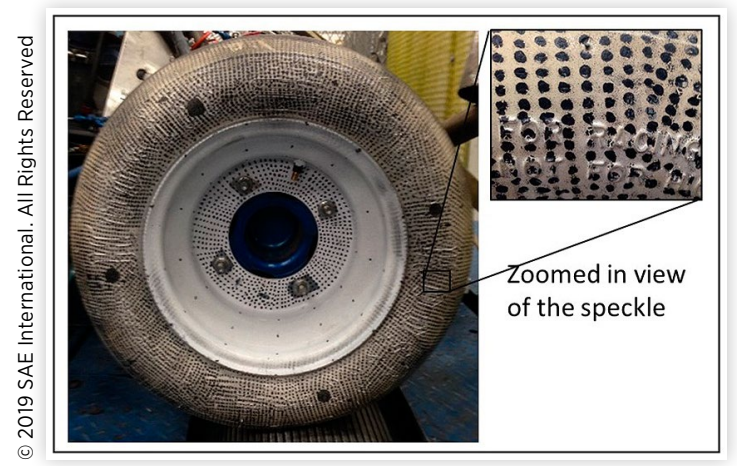


FIGURE 9 Operational deflection shapes of tire sidewall in the unloaded condition at $39.6 \mathrm{~Hz}$ and $65.3 \mathrm{~Hz}$; results obtained using DIC system.
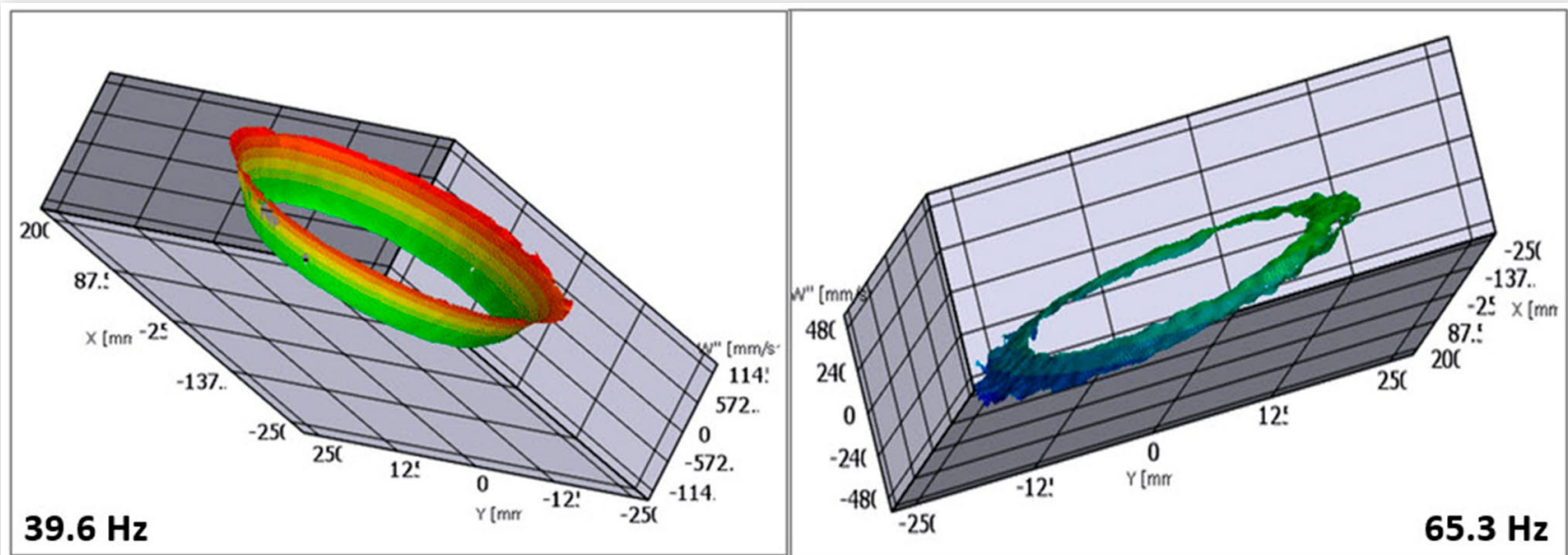

between the resonant frequencies and the operational deflection shapes of Figure 9 (obtained from the DIC system) compared with the equivalent results shown in Figure 4 (obtained using conventional modal analysis techniques). These results effectively validate the output from the DIC system through highly favorable comparisons with similar results obtained from the conventional impact hammer testing method. A comparison between tire resonant frequencies for the two physical testing methods is provided in Table 1. From Table 1 it can be seen that the frequencies as determined using the DIC approach are within one percent of those established using conventional modal analysis methods.

The same procedure was repeated to perform a test on the tire when it was loaded on the dynamometer. The nonrotating tire was excited at a single point with the impact modal hammer, and the displacement data were obtained by processing the images captured by the high-speed cameras. Transferring the time domain data into the frequency domain showed that the loaded tire had a first resonant frequency of $60 \mathrm{~Hz}$. Figure 10 shows the acceleration response of the tire overlaid on its geometry, along with an FFT response plot and an operational deflection shape. The resonant frequency and

TABLE 1 Comparison of the resonant frequencies of the tire in the unloaded condition obtained using two physical testing methods.

\begin{tabular}{|l|l|l|l|} 
Mode & $\begin{array}{l}\text { Frequency using } \\
\text { conventional method }\end{array}$ & $\begin{array}{l}\text { Frequency } \\
\text { using DIC }\end{array}$ & $\begin{array}{l}\text { Percent } \\
\text { change }\end{array}$ \\
\hline 1 & $39.9 \mathrm{~Hz}$ & $39.6 \mathrm{~Hz}$ & $-1 \%$ \\
\hline 2 & $64.7 \mathrm{~Hz}$ & $65.3 \mathrm{~Hz}$ & $+1 \%$ \\
\hline
\end{tabular}

operational deflection shape obtained using DIC match with the natural frequency and mode shape acquired using the conventional impact hammer approach. Table 2 lists the comparison between the resonant frequencies for the loaded condition. The frequency as determined using the DIC approach is within one percent of that established using conventional modal analysis methods.

The high percent change is because of change in the boundary condition between the unloaded and loaded test. Also, the percent change results from the two methods are almost the same (as can be seen from Tables 3 and $\underline{4}$ ).

\section{Operational Modal Analysis Using DIC}

After validating the DIC data for the tire in the non-rotating conditions, the DIC system was extended for use in the rotating test cases. Figure 11 shows the FFT of the response for the case when the tire is rotating at $5 \mathrm{MPH}$.

DIC measurements were also performed on the tire when it rotated at higher speeds. For those measurements, the camera frame rate increased from $500 \mathrm{fps}$ to $1000 \mathrm{fps}$, and the shutter time was decreased to reduce the motion blur. The tire underwent continuous cyclic excitations when it was rotating on the dynamometer. Additionally, there were multiple cleats present on the drum roller of the dynamometer that provided excitations to the tire. Due to the complex nature of the excitations from the dynamometer system, it is challenging to identify the cause for each of the tire modes that were identified during testing. 
FIGURE 10 DIC results for the stationary tire in a loaded condition: (a) overlay of the acceleration response on the tire geometry, (b) FFT plot of the measured response, and (c) operational deflection shape of the tire at $60 \mathrm{~Hz}$.

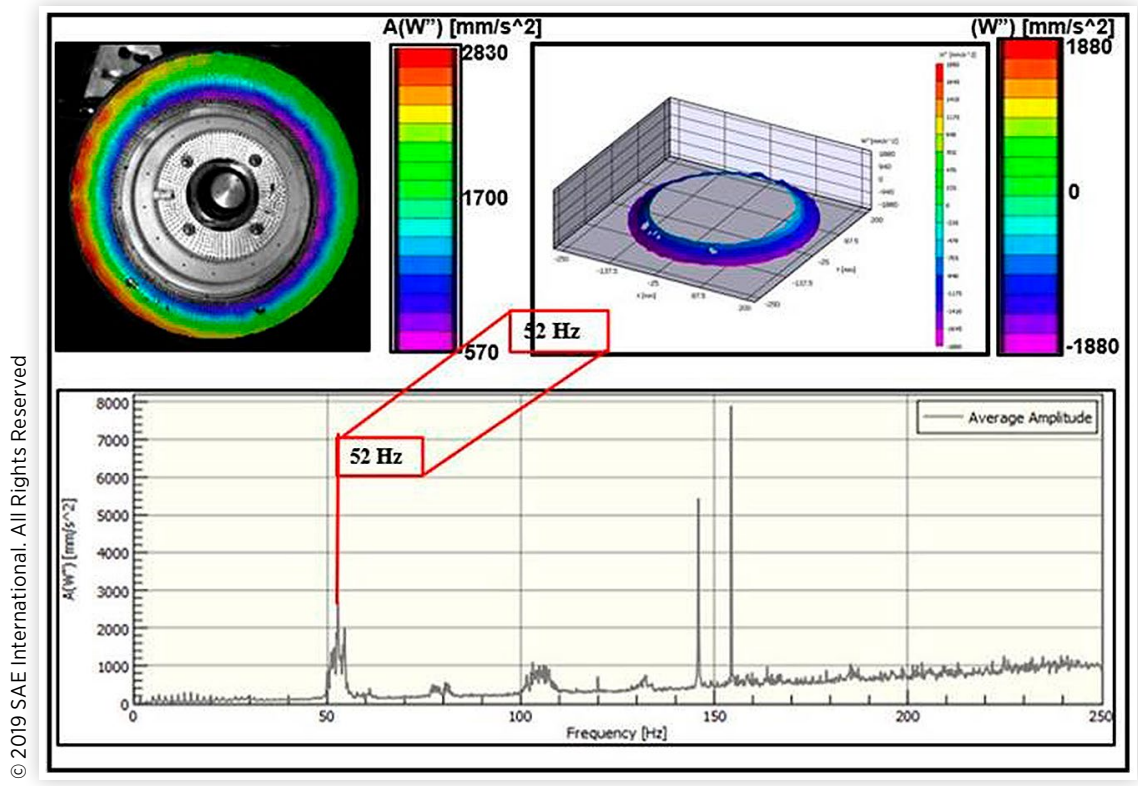

Figures $12, \underline{13}$, and $\underline{14}$ show the full-field acceleration response, FFT plots, and operational deflection shapes of the rotating tire at speeds of 18,30 , and $40 \mathrm{MPH}$, respectively. The results indicate that DIC is a robust technique to obtain the modal characteristics of tires at high rotating speeds. As can be seen, the FFT plots show multiple peaks. Some of these peaks occurred because there were many radial modes of the tire that were excited; however, these modes were not fully captured in the side view. Also, the rotation of the tire can disturb the symmetry for repeated root modes. On the other hand, some of these peaks correlated with operating deflection shapes of the tire due to the rotation of the tire.

TABLE 2 Comparison of the resonant frequencies of the tire in the loaded condition obtained using two physical testing methods.

\begin{tabular}{|l|l|l|l|}
\hline Mode & $\begin{array}{l}\text { Frequency using } \\
\text { conventional method }\end{array}$ & $\begin{array}{l}\text { Frequency } \\
\text { using DIC }\end{array}$ & $\begin{array}{l}\text { Percent } \\
\text { change }\end{array}$ \\
\hline 1 & $59.4 \mathrm{~Hz}$ & $60 \mathrm{~Hz}$ & $+1 \%$ \\
\hline
\end{tabular}

TABLE 3 Comparison of the resonant frequencies of the tire in the unloaded and loaded condition obtained using the conventional impact hammer testing.

\begin{tabular}{|c|c|c|c|}
\hline Mode & $\begin{array}{l}\text { Unloaded } \\
\text { condition }\end{array}$ & $\begin{array}{l}\text { Loaded } \\
\text { condition }\end{array}$ & $\begin{array}{l}\text { Percent } \\
\text { change }\end{array}$ \\
\hline 1 & $39.9 \mathrm{~Hz}$ & $59.4 \mathrm{~Hz}$ & $+39.2 \%$ \\
\hline
\end{tabular}

The operating shapes shown in Figures 12-14 is related to one of the prominent peaks. More modes are shown in Figure 15. The dominating effect of harmonics (of the tire rotation frequency) makes it difficult to identify the actual modes of the tire. Further processing and research need to be carried out in order to eliminate the harmonics to better understand the vibration characteristics of the tire.

Table 5 shows that the resonant frequency of the tire changes in rotating condition as the mass and stiffness concentration would change with the rolling conditions.

\section{Discussion}

Figure 15 shows the operational deflection shapes of the tire at a constant speed of $40 \mathrm{MPH}$. As the image indicates, the number of lobes in the operational deflection shape has increased compared with the non-rotating cases. This shows that the rotation of a tire can significantly change the dynamic characteristics of the tire. Some of these modes can also be excited at the rotating frequency and its harmonics. The tire had a diameter of approximately 18 inches. The rotational

TABLE 4 Comparison of the resonant frequencies of the tire in the unloaded and loaded condition obtained using DIC.

\begin{tabular}{|llll} 
Mode & $\begin{array}{l}\text { Unloaded } \\
\text { condition }\end{array}$ & $\begin{array}{l}\text { Loaded } \\
\text { condition }\end{array}$ & $\begin{array}{l}\text { Percent } \\
\text { change }\end{array}$ \\
\hline 1 & $39.6 \mathrm{~Hz}$ & $60 \mathrm{~Hz}$ & $+40.9 \%$ \\
\hline & & ( ) 2019 SAE International. All Rights Reserved
\end{tabular}


FIGURE 11 DIC results for the rotating tire at $5 \mathrm{MPH}$ : (a) overlay of the acceleration response on the tire geometry, (b) FFT plot of the measured response, and (c) operational deflection shape of the tire at $52 \mathrm{~Hz}$.



speed for this tire with a translational speed of $40 \mathrm{MPH}$ was 800 RPM. This rotational speed equates to a fundamental frequency of $13.33 \mathrm{~Hz}$. The third, fourth, and fifth harmonics of the rotational frequency correspond to $40.0 \mathrm{~Hz}, 53.3 \mathrm{~Hz}$, and $66.7 \mathrm{~Hz}$, respectively. As shown in Figure 15, the operational deflection shape of the tire has three lobes at $38.9 \mathrm{~Hz}$, which is the third harmonic of the rotation frequency. Similarly, at a frequency of $104.1 \mathrm{~Hz}$, which is the eighth harmonic, the operational deflection shape of the tire has eight lobes. Because the harmonics have a dominating effect, it is essential to attenuate their effects.

The results in Figure 13 can be interpreted by considering the contact patch force. When the tire is rotating, a force is applied to the contact area of the tire. If the tire is analyzed in a rotating coordinate system, that is, a moving frame of reference that is fixed to the tire, then from the perspective of an observer in the

FIGURE 12 DIC results for the rotating tire at $18 \mathrm{MPH}$ : (a) overlay of the acceleration response on the tire geometry, (b) FFT plot of the measured response, and (c) operational deflection shape of the tire at $64 \mathrm{~Hz}$.

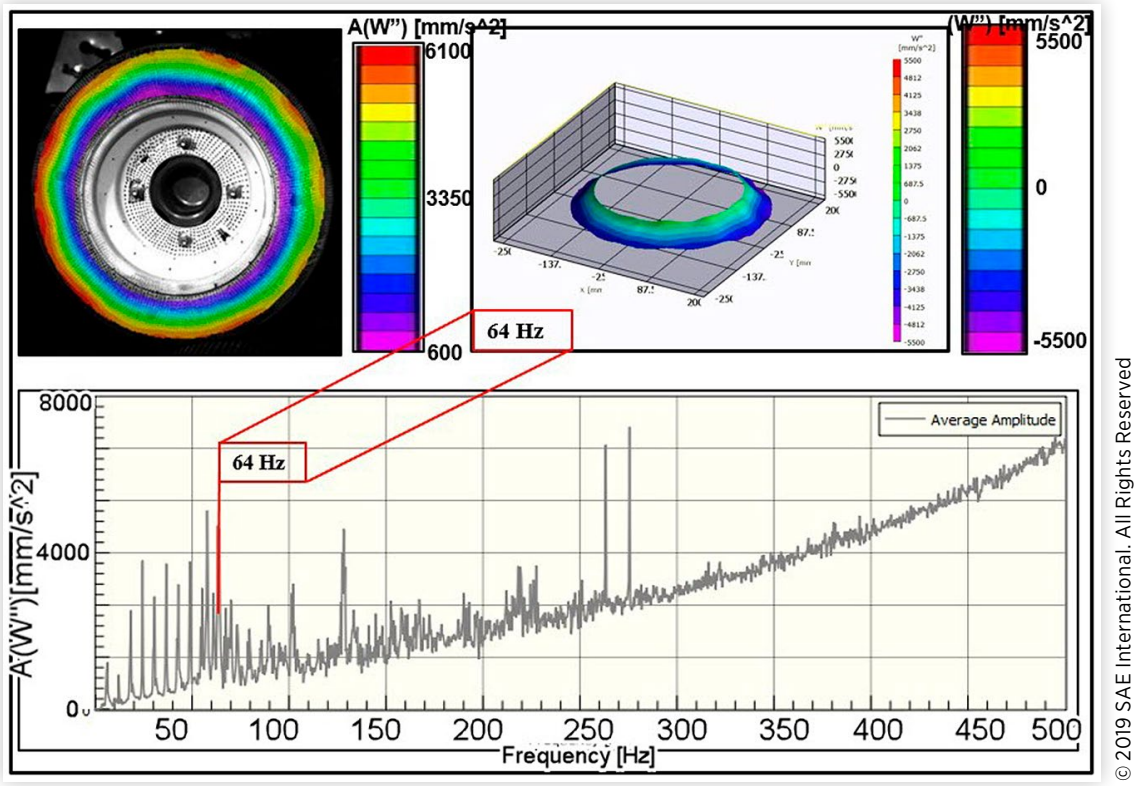


FIGURE 13 DIC results for the rotating tire at $30 \mathrm{MPH}$ : (a) overlay of the acceleration response on the tire geometry, (b) FFT plot of the measured response, and (c) operational deflection shape of the tire at $139 \mathrm{~Hz}$.

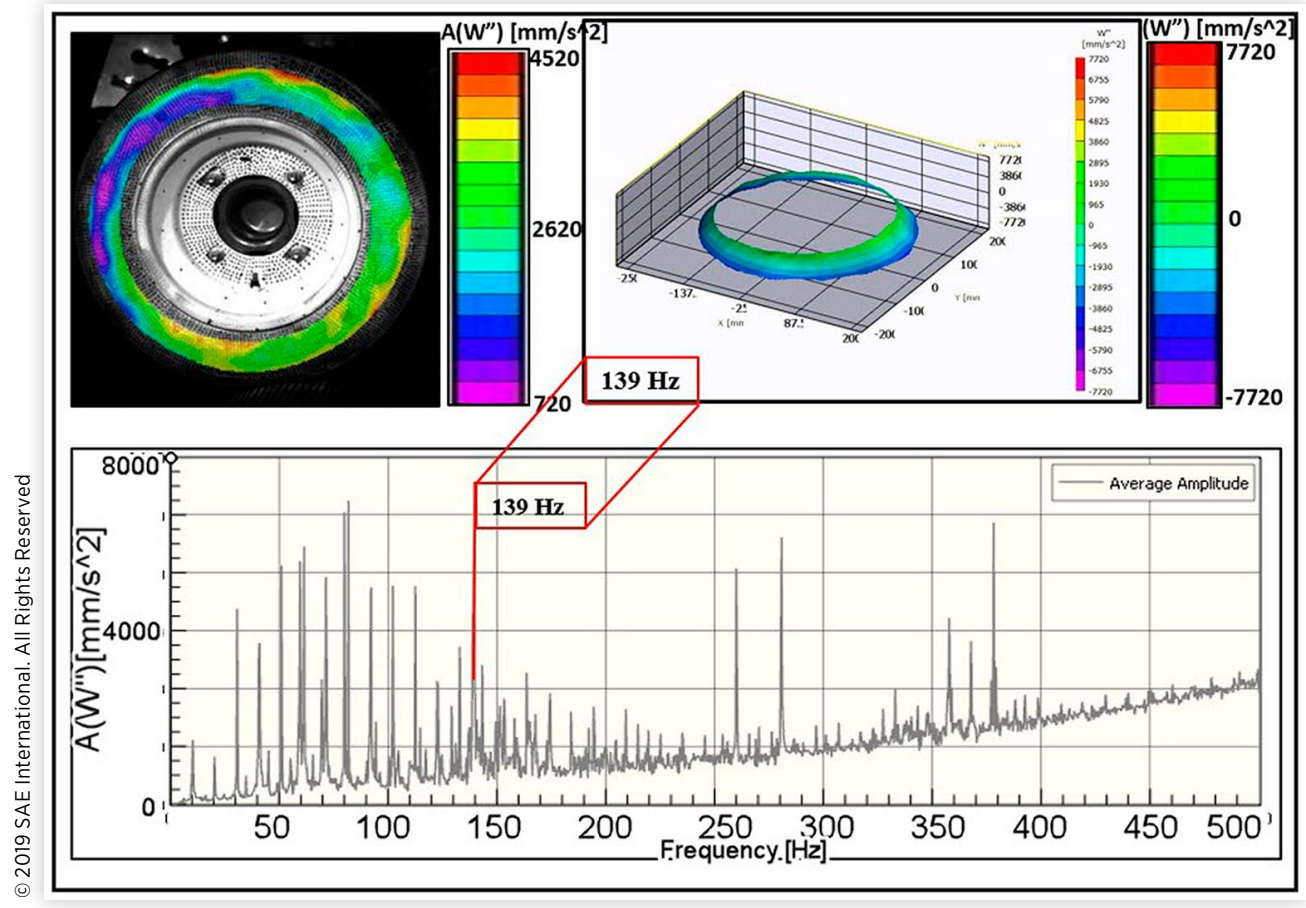

FIGURE 14 DIC results for the rotating tire at $40 \mathrm{MPH}$ : (a) overlay of the acceleration response on the tire geometry, (b) FFT plot of the measured response, and (c) operational deflection shape of the tire at $86 \mathrm{~Hz}$.

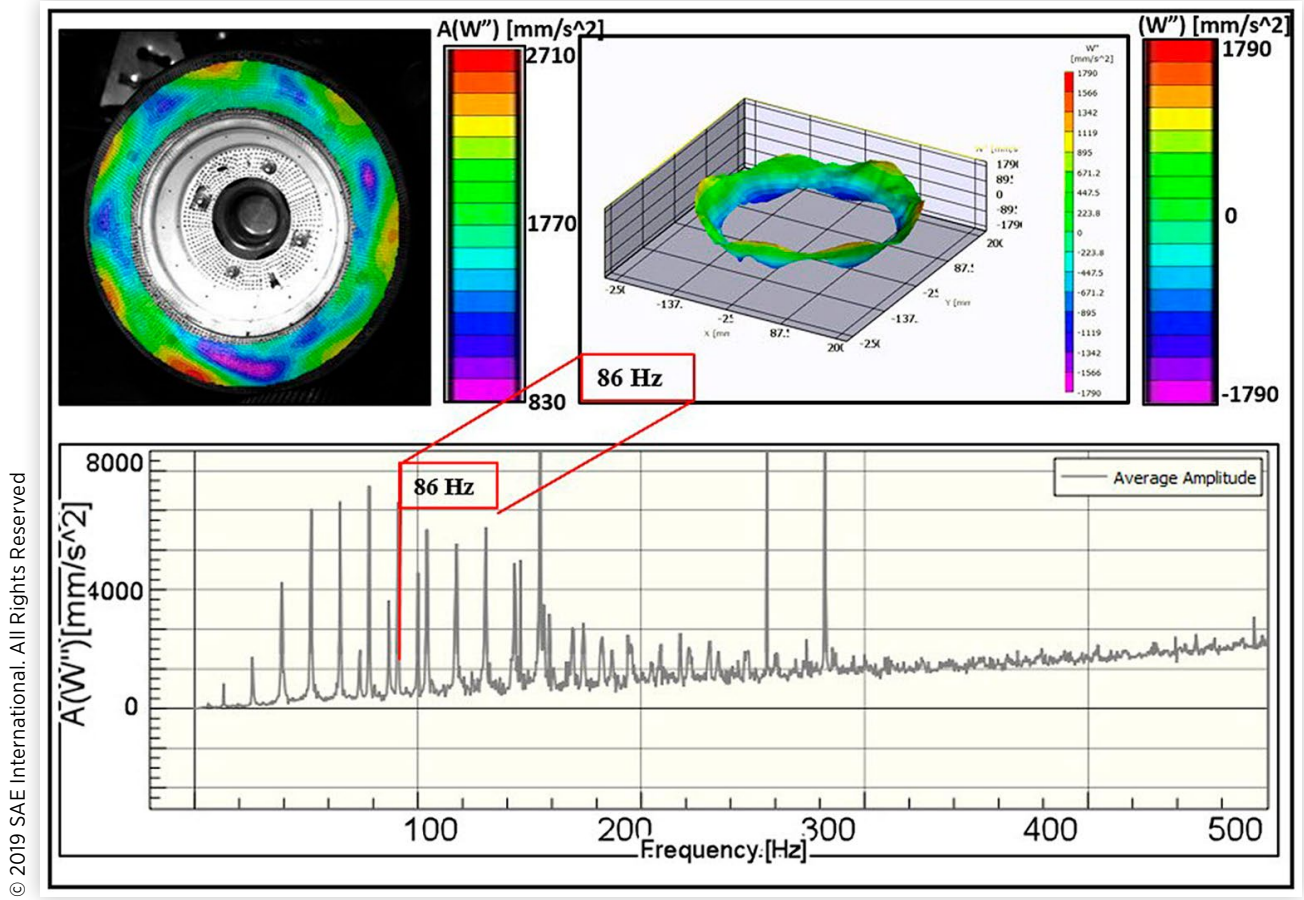




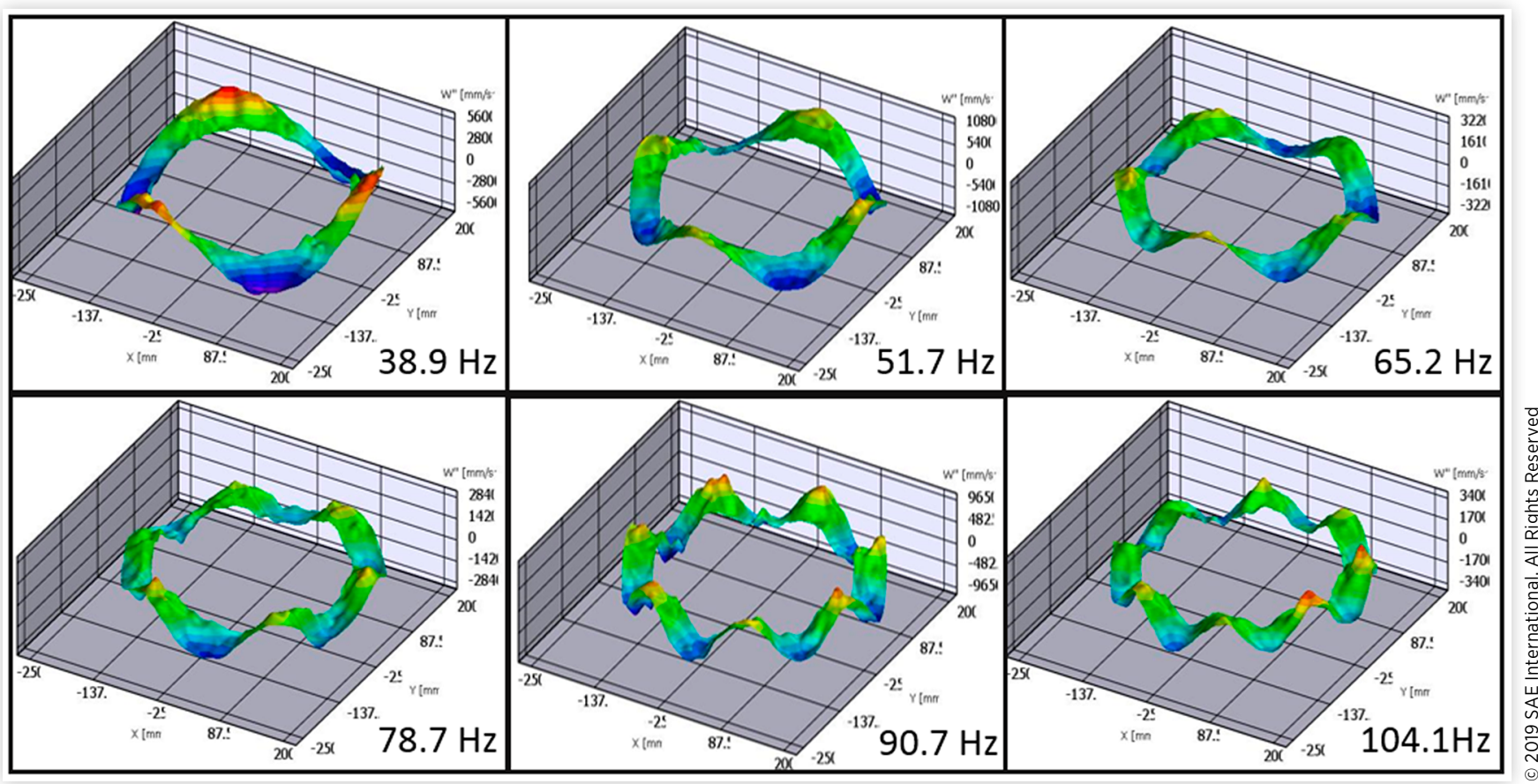

moving frame $e^{1}$ there is a contact patch force that rotates on the tire. In fact, the test condition can be modeled as a fixed tire subjected to a rotating force. This harmonically rotating force can excite the tire and generate dynamic deformation shapes. Thus, the harmonics of the rotating force will also be present in the operational deflection shapes as shown in Figure 13.

\section{Conclusion}

In this article, DIC was used to obtain the vibration characteristics of a rotating tire. Conventional impact hammer modal testing was carried out to acquire the vibrational

TABLE 5 Comparison of the resonant frequencies of the tire in non-rotating and rotating conditions obtained using DIC.

\begin{tabular}{|c|c|c|c|}
\hline Mode & $\begin{array}{l}\text { Frequency in } \\
\text { non-rotating } \\
\text { loaded condition }\end{array}$ & $\begin{array}{l}\text { Frequency in rotating } \\
\text { conditions }\end{array}$ & $\begin{array}{l}\text { Percent } \\
\text { change }\end{array}$ \\
\hline \multirow[t]{4}{*}{1} & $60 \mathrm{~Hz}$ & $52 \mathrm{~Hz}$ (for $5 \mathrm{MPH}$ ) & $-14.2 \%$ \\
\hline & & $64 \mathrm{~Hz}$ (for $18 \mathrm{MPH}$ ) & $+6.4 \%$ \\
\hline & & $139 \mathrm{~Hz}$ (for $30 \mathrm{MPH}$ ) & $+79.3 \%$ \\
\hline & & $86 \mathrm{~Hz}$ (for $40 \mathrm{MPH}$ ) & $+35.6 \%$ \\
\hline
\end{tabular}

(c) 2019 SAE International. All Rights Reserved

\footnotetext{
${ }^{1}$ The usual convention is assumed here, in that the observer rotates with the moving frame and is "welded" to it.
}

characteristics of the Kettering University FSAE tire. The natural frequencies and mode shapes of the tire were obtained in different loading conditions. DIC was used for the same test cases and the results compared very well with those obtained from conventional testing methods. The DIC approach was also implemented for the rotating test conditions of the FSAE tire. The vehicle was loaded on the dynamometer and the tire was excited through the drum roller at different rolling speeds. The results exhibit the different resonant frequencies and operational deflection shapes of the tire that were captured using DIC. On the other hand, it was shown that, when the effects of the harmonics are not dominant, the resonant frequencies for the actual modes of the tire decreases as the rotation speed increases. Upon further analysis of the frequency domain information for the tire in rotating conditions, it is observed that there are many dominant peaks in the FFT plots that can be associated with harmonics of the fundamental tire rotation frequency.

The noncontact DIC technique successfully captures the vibration responses of the tire in rolling conditions, which is difficult to obtain using the conventional technique of modal analysis. DIC is a robust method that has a shorter processing time when compared with the other noncontact techniques such as Laser Doppler Vibrometry. The noncontact DIC technique provides the full-field response of the tire, and it can also be used to extract the displacement and strain data simultaneously. The results indicate that rotating tires can have operating deflection shapes that may not exist or may not be excited when stationary. These operating 
shapes generally corresponded to the harmonics of the fundamental rotation frequency. This signifies that the rolling condition of the tire greatly affects its dynamic properties and its dynamic response.

\section{Contact Information}

Javad Baqersad

jbaqersad@kettering.edu

\section{Definitions/Abbreviations}

DIC - Digital image correlation

FFT - Fast Fourier transform

fps - Frames per second

FRF - Frequency response function

LED - Light emitting diode

LDV - Laser Doppler vibrometer

MPH - Miles per hour

NVH - Noise, vibration, harshness

RPM - Revolutions per minute

\section{References}

1. Kindt, P., DeConinck, F., Sas, P., Desmet, W., "Experimental Modal Analysis of Radial Tires and the Influence of Tire Modes on Vehicle Structure Borne Noise", Proceedings of the 31st FISITA 2006, Word Automotive Congress, Yokohama, Japan, 2006.

2. Niskanen, A.J. and Tuononen, A.J., "Three 3-Axis Accelerometers Fixed Inside the Tyre for Studying Contact Patch Deformations in Wet Conditions," Vehicle System Dynamics 52:287-298, 2014.

3. Patil, K., Baqersad, J., and Bastiaan, J., "Effects of Boundary Conditions and Inflation Pressure on the Natural Frequencies and 3D Mode Shapes of a Tire," SAE Technical Paper 2017-01-1905, 2017, doi:10.4271/2017-01-1905.

4. Tuononen, A.J., "Laser Triangulation to Measure the Carcass Deflections of a Rolling Tire," Measurement Science and Technology 22:125304, 2011.

5. Lee, J., Wang, S., Kindt, P., Pluymers, B., and Desmet, W., "Identification of the Direction and Value of the Wave Length of Each Mode for a Rotating Tire Using the Phase Difference Method," Mechanical Systems and Signal Processing 68:292-301, 2016.

6. Chu, T., Ranson, W., and Sutton, M., "Applications of Digital-Image-Correlation Techniques to Experimental Mechanics," Exp Mech 25:232-244, 1985.
7. Sutton, M., Wolters, W., Peters, W., Ranson, W., and McNeill, S., "Determination of Displacements Using an Improved Digital Correlation Method," Image and Vision Computing 1:133-139, 1983.

8. Peters, W.H. and Ranson, W.F., "Digital Imaging Techniques in Experimental Stress Analysis," OPTICE 21:213427, 1982, doi:10.1117/12.7972925.

9. Sutton, M.A., Orteu, J.J., and Schreier, H., Image Correlation for Shape, Motion and Deformation Measurements: Basic Concepts, Theory and Applications (New York: Springer Science \& Business Media, 2009).

10. Reu, P., "Introduction to Digital Image Correlation: Best Practices and Applications," Experimental Techniques 36:34, 2012.

11. Baqersad, J., Carr, J., Lundstrom, T., Niezrecki, C., Avitabile, P., and Slattery, M., "Dynamic Characteristics of a Wind Turbine Blade Using 3D Digital Image Correlation," in SPIE Smart Structures and Materials+ Nondestructive Evaluation and Health Monitoring, San Diego, CA, Vol. 8348, 2012, International Society for Optics and Photonics, 83482I.

12. Carr, J., Baqersad, J., Niezrecki, C., Avitabile, P., and Slattery, M., "Dynamic Stress-Strain on Turbine Blades Using Digital Image Correlation Techniques Part 2: Dynamic Measurements," in Topics in Experimental Dynamics Substructuring and Wind Turbine Dynamics, Vol.2, (New York: Springer, 2012), 221-226.

13. Panchal, R., Horton, L., Poozesh, P., Baqersad, J., and Nasiriavanaki, M., "Vibration Analysis of Healthy Skin: Towards a Novel Non-Invasive Skin Diagnosis Methodology," BIOMEDO 24:1-11, 2019, doi:10.1117/1. ذBO.24.1.015001.

14. Baqersad, J., Poozesh, P., Niezrecki, C., and Avitabile, P., "Photogrammetry and Optical Methods in Structural Dynamics - A Review," Mechanical Systems and Signal Processing 86: Part B, 17-34, 2017, doi:10.1016/j. ymssp.2016.02.011.

15. Niezrecki C., Baqersad J., and Sabato A., "Digital Image Correlation Techniques for NDE and SHM,"in Handbook of Advanced Non-Destructive Evaluation, (2018),1-46, Springer, Cham, doi:10.1007/978-3-319-30050-4 47-1.

16. Kim, S.-W. and Kim, N.-S., "Dynamic Characteristics of Suspension Bridge Hanger Cables Using Digital Image Processing," NDT\&E International 59:25-33, 2013, doi:10.1016/j.ndteint.2013.05.002.

17. Olaszek, P., "Investigation of the Dynamic Characteristic of Bridge Structures Using a Computer Vision Method," Measurement 25:227-236, 1999, doi:10.1016/S02632241(99)00006-8.

18. Lee, J.J. and Shinozuka, M., "A Vision-Based System for Remote Sensing of Bridge Displacement," NDT\&E International 39:425-431, 2006, doi:10.1016/j. ndteint.2005.12.003.

19. Poozesh, P., Baqersad, J., Niezrecki, C., Avitabile, P. et al., "Large-Area Photogrammetry Based Testing of Wind 
Turbine Blades," Mechanical Systems and Signal Processing 86:97-115, 2016, doi:10.1016/j.ymssp.2016.07.021.

20. Ozbek, M., Rixen, D.J., Erne, O., and Sanow, G., "Feasibility of Monitoring Large Wind Turbines Using Photogrammetry," Energy 35:4802-4811, 2010, doi:10.1016/j. energy.2010.09.008.

21. Kalpoe, D., Khoshelham, K., and Gorte, B., "Vibration Measurement of a Model Wind Turbine Using High Speed Photogrammetry," in Videometrics, Range Imaging, and Applications XI, Munich, Germany, May 25-May 26, 2011, The Society of Photo-Optical Instrumentation Engineers (SPIE), doi: 10.1117/12.889440.

22. Poozesh, P., Sarrafi, A., Mao, Z., Avitabile, P., and Niezrecki, C., "Feasibility of Extracting Operating Shapes Using PhaseBased Motion Magnification Technique and StereoPhotogrammetry," Journal of Sound and Vibration 407:350366, 2017, doi:10.1016/j.jsv.2017.06.003.

23. Lundstrom, T., Baqersad, J., and Niezrecki, C., "Monitoring the Dynamics of a Helicopter Main Rotor with High-Speed Stereophotogrammetry," Experimental Techniques 40:907919, 2015, doi:10.1111/ext.12127.

24. Caprioli, A., Manzoni, S., and Zappa, E., "People-Induced Vibrations of Civil Structures: Image-Based Measurement of Crowd Motion," Experimental Techniques 35:71-79, 2011, doi:10.1111/j.1747-1567.2009.00574.x.
25. Zbožínek, V., Tomčík, P., Kulhánek, J., Fojtík, P., Buráň, M., and Suchánek, M., "Car Axle Testing on Hydropulse," in 18th International Carpathian Control Conference (ICCC), IEEE, Sinaia, Romania, 2017, 1-4.

26. Patil, K., Srivastava, V., and Baqersad, J., "A Multi-View Optical Technique to Obtain Mode Shapes of Structures," Measurement 122:358-367, 2018, doi:10.1016/j. measurement.2018.02.059.

27. Kindt, P., delliCarri, A., Peeters, B., Van der Auweraer, H., Sas, P., and Desmet, W., "Operational Modal Analysis of a Rotating Tyre Subject to Cleat Excitation," in Structural Dynamics, Vol.3 (New York: Springer, 2011), 1501-1512.

28. Niezrecki, C., Reu, P., Baqersad, J., and Rohe, D., "DIC and Photogrammetry for Structural Dynamic Analysis and High-Speed Testing," in Allemang, R. and Avitabile, P. (eds), Handbook of Experimental Structural Dynamics (Cham: Springer, 2021).

29. Srivastava, V. and Baqersad, J., "An Optical-Based Technique to Obtain Operating Deflection Shapes of Structures with Complex Geometries," Mechanical Systems and Signal Processing 128:69-81, 2019.

30. Gillespie, T.D., "Fundamentals of Vehicle Dynamics," (Warrendale, PA: Society of Automotive Engineers, 1992), Product Code: R-114, doi:10.4271/R-114. 